\section{P121 A REVIEW OF THE TELEPHONE ADVICE SERVICE FOR CENTRAL AND NORTH WEST LONDON INTEGRATED SEXUAL HEALTH SERVICES}

Sophie Flavell*, Chloe Gillon, Sophie Molloy, Breda Curran, Danielle Mercey, Rachel D'Souza, Eva Jungmann. Central and North West London NHS Foundation Trust, London, UK

\subsection{6/sextrans-2015-052126.164}

Background/introduction Although not advertised patients can phone our integrated sexual health services for advice and receive a call-back within $24 \mathrm{~h}$. This service takes up significant resources without being funded.

Aim(s)/objectives Review the reasons for advice calls and establish their outcomes.

Methods A notes review was conducted of 50 calls received at each of the 3 main clinical sites in Central London over a 2 week period in July 2014. Data was collected regarding the reason for the phone call, call outcome and attendance within 6 weeks following the call.

Results The majority $129 / 150(86 \%)$ of calls were from existing patients. The majority of phone advice was related to contraception $\mathrm{n}=44 / 160(28 \%)$, advice on sexually transmitted infections $\mathrm{n}=22 / 160(14 \%)$ and patients with symptoms $\mathrm{n}=31 / 160$ (19\%). 24/44(66\%) of the contraception calls were for intrauterine device (IUD) advice (pre-and post-insertion). 50/150(33\%) patients were advised to attend the clinic of whom 39/50(78\%) did attend. 66/150(44\%) patients were given reassurance of whom $12 / 66(18 \%)$ attended anyway related to their call.

Discussion The phone advice service was largely used by existing users and almost $40 \%$ attended the service after the phone call. To make more effective use of resources we have designed frequently answered questions (FAQ) page on our website to address the most commonly asked questions. Phone advice is now only available to patients on post-exposure prophylaxis (PEP) and post-procedure eg. IUD insertion.

\section{P122 WALK-IN PRIMARY-CARE CENTRES ARE ACCEPTABLE TO MEN WHO HAVE SEX WITH MEN (MSM)}

Tamuka Gonah*, Jodie Scrivener, Isata Gando, Rageni Sangha, Daniel Richardson. Brighton and Sussex University Hospital, Brighton, Sussex, UK

\subsection{6/sextrans-2015-052126.165}

Background Locally we have the highest HIV prevalence outside London and high rates of STIs in MSM. We operate a primarycare centre adjacent to a main line railway station which delivers both primary care and sexual health services. The aim of this study was to assess the acceptability of MSM in this setting.

Method Patient satisfaction survey was offered to MSM attending both services between June and October 2014.

Results $70 / 80(87.5 \%)$ surveys were returned. The median age of participants was 26(16-68) years. 62/70(89\%) described themselves as MSM and 7/70 bisexual. 65/70(93\%) attended for a sexual health screen. MSM liked the service due to ease of access (47\%), proximity to work (23\%) and opening-hours (23\%). MSM highly rated welcome by reception staff $(73 \%$ rated $5 / 5)$ and welcome by health-care-worker (HCW) (93\% rated 5/5). $69 / 70(99 \%)$ stated they felt comfortable discussing their sexuality with the HCW. 46/70(66\%) strongly agreed that the clinic environment was friendly to MSM. 29-freetext comments were received: 14/28(48\%) were positive and 10/28(35\%) offered service improvement suggestions: MSM suggested that streamlining appointment-booking and results via internet/ mobile-phones and more evening appointments would improve the current service for them. Of concern, only 5/70(7\%) of MSM attending for non-sexual health were offered STI testing. Conclusion Our primary care centre offers a highly acceptable service for MSM. Electronic booking and results, and increased evening appointments will increase acceptability. We need to increase STI testing among MSM attending for general practice issues.

\section{P123 ENGAGING HIGH RISK POPULATIONS IN SEXUAL WELLBEING PROGRAMMES}

David Stuart*, Leigh Chislett. Chelsea and Westminster Hospital NHS Foundation Trust, London, UK

\subsection{6/sextrans-2015-052126.166}

Background/introduction Our NHS GUM/HIV clinic caters to a number of high risk populations, including transgender people, and MSM who use drugs for sex (the practice commonly known as 'ChemSex'). Simply attracting these populations to our clinics, screening and treating for infections is not providing our patients with the robust care they deserve and need; in order to have any significant impact on infection rates, we need to offer culturally competent, holistic care that addresses the broader needs of the individual. In 2014, our team established the Wellbeing programme; a series of community engagement events that addressed the sexual and general wellbeing of individuals and communities via film screenings, community discussions, performance art, poetry and open-mic events; the concept is, that if our patients experienced community cohesion, and individual sexual wellbeing, they would experience less disease, less drug/ alcohol use, less stigma, and better sexual health.

Aim(s)/objectives To place sexual wellbeing at the heart of sexual health, by engaging high risk populations in community dialogues about their own sexual choices, emotional needs and general wellbeing.

Methods Open-mic events, art exhibitions, discussion evenings with porn performers and scene personalities on relevant controversial topics.

Results Successful attendances at events, winning the faith of high risk populations, engagement with our clinics.

Discussion/conclusion This oral presentation will use footage from events and an interactive discussion on how to engage local populations or engagement-resistant cohorts in treatment.

\section{P124 WHAT IS THE ROLE OF GENERAL PRACTICE AND THE POTENTIAL BARRIERS IN PROVIDING SHARED CARE FOR PEOPLE LIVING WITH HIV: A SYSTEMATIC REVIEW}

Lois Hawkins*, Jackie Cassell. Brighton and Sussex Medical School, Brighton, UK

10.1136/sextrans-2015-052126.167

Background/introduction Traditionally hospital based GUM/HIV departments have cared for people living with HIV (PLWHIV). Due to increased survival, HIV is now a chronic disease where many PLWHIV suffer from age associated illnesses. Management by generalists for such conditions is therefore essential. Shared care, however, is variably provided. We assessed the evidence on the provision and quality of shared care for PLWHIV to inform future service provision. 
Aims To collate and assess the existing literature on the role of and barriers to the GP providing shared care for PLWHIV.

Methods MEDLINE, PsycINFO and EMBASE were searched using MESH terms "HIV" or "AIDS" combined with "general practice" or "primary health care". Empirical studies from developed countries relating to the role, involvement or barriers of GP utilisation in shared care were used. Eleven research articles were eligible for this review.

Results Most GPs and patients want to engage in shared care. 81-89\% PLWHIV were registered with a GP and 78\% had disclosed their status. Potential barriers included lack of specialist knowledge, accessibility, issues of confidentiality and stigmatisation, and poor communication between services. GP engagement was dependent on their experience with HIV, local prevalence of HIV and patient level of morbidity.

Conclusions This review demonstrated large variations between UK health service provisions for PLWHIV. Disclosure to GPs has improved in the post-HAART (highly active antiretrovirals) era; however remaining barriers to shared care, primarily communication between services, needs to be addressed. Further research to develop models of shared care for PLWHIV is necessary to provide comprehensive safe, good quality care.

\section{P125 IMPROVING CLINICAL STANDARDS IN GU MEDICINE: A RETROSPECTIVE AUDIT OF NEISSERIA GONORRHOEAE}

Jessica Jefferson*, Sris Allan. Coventry and Warwickshire Partnership Trust, Coventry, UK

\subsection{6/sextrans-2015-052126.168}

Background This was a retrospective analysis of clinic performance in the management and treatment of Neisseria gonorrhoeae (GC) according to current British Association of Sexual Health and HIV (BASHH) guidelines.

Methods All cases of GC diagnosed at our clinic between $1^{\text {st }}$ January and $30^{\text {th }}$ June 2014 were identified. The case notes were reviewed and assessed against current BASHH criteria. This was compared to data collected at the same clinic for the same six months in 2007 to 2014 . The total number of cases identified in 2014 was 126.

Results

Conclusions Current BASHH targets have been achieved in only 1 out of 5 criteria, there was a drop from 100\% (2013) to 97\% (2014) in patients not receiving $1^{\text {st }}$ line treatment. Targets for chlamydia screening/treatment were met. There was very poor performance in offering written advice in 2014 - this is likely due to poor documentation rather than clinical practice. A new facility, implemented during the audit period, on our computer system now gives a visual prompt for recording the provision of written information. This will need to be re-audited in 2015 to look for improvement. We recommend making the input of information to be a compulsory entry before allowing the entry to be saved. Further staff training and awareness of arranging TOC needs to be addressed, and we recommend a re-audit of this next year. We suggest that we should implement a TOC entry facility on our patient record to prompt users to arrange this for the patient.

\section{P126 THE 2014/15 EUROPEAN COLLABORATIVE CLINICAL GROUP (ECCG) SERVICE EVALUATION ON THE MANAGEMENT OF PELVIC INFLAMMATORY DISEASE}

${ }^{1}$ Omome Etomi*, ${ }^{1}$ Sabah Ahmed, ${ }^{1}$ Ben Brooks, ${ }^{2}$ Gilbert Donders, ${ }^{3}$ Mikhail Gomberg, ${ }^{4}$ Peter Greenhouse, ${ }^{5}$ Jorgen Jensen, ${ }^{6}$ Phillipe Judlin, ${ }^{7}$ Jonathan Ross, ${ }^{8}$ Emily Clarke, ${ }^{8}$ Raj Patel. ${ }^{1}$ Southampton Medical School, Southampton, UK; ${ }^{2}$ Antwerp University Hospital, Edegem, Belgium; ${ }^{3}$ Moscow Scientific and Practical Centre of Dermatovenereology and Cosmetology, Moscow, Russia; ${ }^{4}$ Weston Integrated Sexual Health Centre, Bristol, UK; ${ }^{5}$ State Serum Institute, Copenhagen, Denmark; ${ }^{6}$ University Hospital Nancy, Nancy, France; ${ }^{7}$ University Hospitals Birmingham, Birmingham, UK; ${ }^{8}$ Royal South Hants Hospital, Southampton, UK

\subsection{6/sextrans-2015-052126.169}

Background Pelvic Inflammatory Disease (PID) describes a broad spectrum of disease primarily diagnosed clinically, with signs and symptoms lacking both specificity and sensitivity. Mycoplasma genitalium (MG) is being increasingly implicated in cases of non-chlamydial non-gonococcal PID. The core principle of the management of PID remains to maintain a low threshold for diagnosis and treatment to prevent long-term sequelae.

Aim To evaluate the current management of PID amongst sexual health physicians across Europe against the current European guidelines.

Methods A clinical scenario based questionnaire was developed by a panel of European experts on PID, and this was disseminated to a group of 120 sexual health physicians across 38 countries who are members of the European Collaborative Clinical Group (ECCG) - a network of sexual health specialists who conduct questionnaire based research across the European region.

Results Provisional results demonstrate variation in practice across Europe and this is most marked in routine testing for and treatment of MG-associated PID, factors influencing the choice of antibiotic therapy, and action taken when an intrauterine device or system is in situ. Full results will be available by the conference.

Conclusion The management of PID varies across Europe and is not always in line with current European guidelines. There is a need for ongoing Europe wide education to ensure that patients are receiving evidence based care. Furthermore, there are issues

\begin{tabular}{|c|c|c|c|c|c|c|c|}
\hline Criterion & 2007 & 2008 & 2009 & 2011 & 2012 & 2013 & 2014 \\
\hline 1) All patients treated for GC should be recommended to have a test of cure (TOC) & & & & $\begin{array}{l}\text { ( } 36 \% \text { had } \\
\text { a TOC) }\end{array}$ & $\begin{array}{l}91 \%(66 \% \text { had } \\
\text { a TOC) }\end{array}$ & $\begin{array}{l}84.6 \%(52.9 \% \\
\text { had a TOC) }\end{array}$ & $\begin{array}{l}91 \%(60 \% \\
\text { had a TOC) }\end{array}$ \\
\hline $\begin{array}{l}\text { 2) All patients with gonorrhoea should be screened for genital infection with Chlamydia } \\
\text { trachomatis or receive presumptive treatment for this infection }\end{array}$ & $100 \%$ & $100 \%$ & $100 \%$ & $98.6 \%$ & $100 \%$ & $100 \%$ & $100 \%$ \\
\hline $\begin{array}{l}\text { 3) All patients identified with gonorrhoea should have partner notification carried out } \\
\text { according to the published standards of the BASHH Clinical Standards Unit }\end{array}$ & $82 \%$ & $95 \%$ & $92 \%$ & $92 \%$ & $88 \%$ & $90.4 \%$ & $93 \%$ \\
\hline $\begin{array}{l}\text { 4) All patients identified with gonorrhoea should be offered written advice about STls } \\
\text { and their prevention }\end{array}$ & $32 \%$ & $64 \%$ & $81 \%$ & $61 \%$ & $50 \%$ & $66 \%$ & $27 \%$ \\
\hline $\begin{array}{l}\text { 5) All patients with gonorrhoea should receive first-line treatment, or the reasons for } \\
\text { not doing so should be documented }\end{array}$ & $77 \%$ & $96 \%$ & $100 \%$ & $97 \%$ & $88 \%$ & $100 \%$ & $97 \%$ \\
\hline
\end{tabular}

